\title{
Properties of Somatosensory Synaptic Integration in Cerebellar Granule Cells In Vivo
}

\author{
Henrik Jörntell and Carl-Fredrik Ekerot \\ Department of Experimental Medical Sciences, Section for Neuroscience, Biomedical Center F10, SE-221 84 Lund, Sweden
}

In decerebrated, nonanesthetized cats, we made intracellular whole-cell recordings and extracellular cell-attached recordings from granule cells in the cerebellar C3 zone. Spontaneous EPSPs had large, relatively constant peak amplitudes, whereas IPSPs were small and did not appear to contribute substantially to synaptic integration at a short time scale. In many cases, the EPSPs of individual mossy fiber synapses appeared to be separable by their peak amplitudes. A substantial proportion of our granule cells had small receptive fields on the forelimb skin. Skin stimulation evoked explosive responses in which the constituent EPSPs were analyzed. In the rising phase of the response, our analyses indicated a participation of three to four different mossy fiber synapses, corresponding to the total number of mossy fiber afferents. The cutaneous receptive fields of the driven EPSPs overlapped, indicating an absence of convergence of mossy fibers activated from different receptive fields. Also in granule cells activated by joint movements did we find indications that different afferents were driven by the same type of input. Regardless of input type, the temporal patterns of granule cell spike activity, both spontaneous and evoked, appeared to primarily follow the activity in the presynaptic mossy fibers, although much of the nonsynchronized mossy fiber input was filtered out. In contrast to the prevailing theories of granule cell function, our results suggest a function of granule cells as signal-to-noise enhancing threshold elements, rather than as sparse coding pattern discriminators or temporal pattern generators.

Key words: granule cells; mossy fibers; Golgi cells; synaptic transmission; synaptic integration; parallel fibers

\section{Introduction}

Cerebellar granule cells are only 5-8 $\mu \mathrm{m}$ in diameter and have only four dendrites (range, 3-5), which receive one excitatory mossy fiber synapse each (Palay and Chan-Palay, 1974; Cathala et al., 2003). Therefore, they offer an ideal opportunity to study the contribution of individual synaptic afferents in the integration process. From in vitro studies, we know that the excitatory synaptic potentials are large (Silver et al., 1992; D'Angelo et al., 1995) and that inhibitory input from Golgi cells has a strong tonic component (Brickley et al., 1996; Rossi and Hamann, 1998). A study in the anesthetized rat has essentially confirmed these findings in in vivo whole-cell recordings (Chadderton et al., 2004).

However, the integrative properties of granule cells when the afferents are driven by synaptic input in a natural form remain primarily unknown. In the present study, we perform intracellular recordings with the whole-cell patch-clamp technique from granule cells in the $\mathrm{C} 3$ zone of the decerebrate, nonanesthetized cat. The C3 zone is one of the cerebellar sagittal zones (Apps and Garwicz, 2005) in which the cutaneously activated mossy fibers are easily driven and have particularly small and well defined peripheral receptive fields on the forelimb (Garwicz et al., 1998).

\footnotetext{
Received July 11, 2006; revised 0ct. 4, 2006; accepted 0ct. 6, 2006.

This work was supported by the Swedish Research Council (projects K2005-04X-14780-03A and K2006-04X08291-19-3), the Segerfalk Foundation, the Swedish Medical Society, Crafoordska stiftelsen, and Magnus Bergwalls Stiftelse.

Correspondence should be addressed to Dr. Henrik Jörntell, Department of Experimental Medical Sciences, Section for Neuroscience, BMC F10, Tornavägen 10, SE-221 84 Lund, Sweden. E-mail: henrik.jorntell@med.lu.se. DOI:10.1523/JNEUROSCI.2939-06.2006

Copyright $\odot 2006$ Society for Neuroscience $\quad 0270-6474 / 06 / 2611786-12 \$ 15.00 / 0$
}

In this system, mossy fibers with similar or overlapping receptive fields are terminating together in a somatotopical organization, and the activation kinetics on skin stimulation has been studied (Garwicz et al., 1998). Also, Golgi cells with specific cutaneous receptive fields are distributed according to the same organization (Ekerot and Jörntell, 2001), and because their axons are distributed locally, cutaneously activated inhibitory input to granule cells may be expected to arise from about the same skin area as the excitatory input.

Important issues that could be addressed with these recordings are as follows: (1) the behavior of small neurons when receiving natural spatiotemporal patterns of excitatory/inhibitory synaptic input in a nonanesthetized in vivo preparation; (2) the information content of granule cell-parallel fiber spikes: what spatiotemporal transformations do they represent (i.e., what are the convergence patterns of excitatory and inhibitory afferents on granule cells and how is the temporal pattern of mossy fiber input transformed to granule cell spikes that are conducted up to the molecular layer in the parallel fibers)?

These are fundamental issues for cerebellar physiology that also will provide an evaluation of current models of cerebellar granule cell function. Our data provide little support for a role of granule cells as pattern discriminators, sparse coders, and/or temporal pattern generators but instead suggest that granule cells have a simpler, more straightforward function as signal-to-noiseenhancing threshold detectors.

\section{Materials and Methods}

Adult cats were prepared as described previously (Ekerot and Jörntell, 2001; Jörntell and Ekerot, 2002, 2003). Briefly, after an initial anesthesia 
with propofol (Diprivan; Zeneca, Macclesfield Cheshire, UK), the animals were decerebrated at the intercollicular level and mounted in a stereotaxic frame. The animals were artificially ventilated, and the endexpiratory $\mathrm{CO}_{2}$, blood pressure, and rectal temperature were monitored continuously and maintained within physiological limits. Drainage of CSF, pneumothorax, and clamping the spinal processes of a few cervical and lumbar vertebral bodies served to increase the mechanical stability of the preparation. Our EEG recordings were characterized by a background of periodic $1-4 \mathrm{~Hz}$ oscillatory activity, periodically interrupted by large-amplitude $7-14 \mathrm{~Hz}$ spindle oscillations lasting for $\geq 0.5 \mathrm{~s}$. These forms of EEG activities are normally associated with deep stages of sleep (cf. Niedermeyer and Lopes da Silva, 1993). The pattern of EEG activity and the blood pressure remained stable, also on noxious stimulation, throughout experiments.

Recordings and stimulation. The initial delineation of the forelimb area of the $\mathrm{C} 3$ zone in the cerebellar anterior lobe and the continuous monitoring of the general condition in the sensitive mossy fiber $\rightarrow$ granule cell $\rightarrow$ parallel fiber pathway were performed as described previously (Ekerot and Jörntell, 2001; Jörntell and Ekerot, 2002). Also, the general recording procedures and the procedures for placing stimulation electrodes in the inferior olive and among the superficial parallel fibers have been described in detail previously (Jörntell and Ekerot, 2003). Electrical stimulation of mossy fiber afferents was used to study the properties of directly activated mossy fiber synapses. This stimulation was made with tungsten-in-glass microelectrodes inserted in another sagittally aligned folium of the $\mathrm{C} 3$ zone (transfolial activation), around the anterior interposed nucleus (supranuclear), or in the lateral reticular nucleus (LRN).

Patch-clamp electrodes were pulled to 13-30 M $\Omega$ from borosilicate glass capillaries on a vertical puller (NN-850; Narishige, Tokyo, Japan) and filled with a solution containing (in $\mathrm{mM}$ ) $135 \mathrm{~K}$-gluconate, $7 \mathrm{KCl}, 0.1$ $\mathrm{CaCl}_{2}, 10$ HEPES, and $2 \mathrm{Mg}$-ATP, or with an alternative solution containing (in $\mathrm{mM}$ ) $135 \mathrm{~K}$-gluconate, $7 \mathrm{KCl}, 2 \mathrm{EGTA}, 10 \mathrm{HEPES}$, and 2 $\mathrm{Mg}$-ATP. The solution was titrated to $\mathrm{pH} 7.35-7.40$ using $\mathrm{KOH}$. In some cases, 1-3\% neurobiotin (Vector Laboratories, Burlingame, CA) or biocytin (Sigma, St. Louis, MO) was included in the recording solution to allow postmortem morphological reconstructions of the recorded neurons. Histological procedures for biocytin were as described previously (Jörntell and Ekerot, 2003). Sections stained with neurobiotin were processed using streptavidin Alexa-488 conjugate (Invitrogen, Eugene, OR) in $1 \%$ bovine serum albumin overnight. Stained cells were analyzed in a confocal microscope (LSM 510; Zeiss, Oberkochen, Germany). The junction potential between the electrode solution and the extracellular (EC) environment of the cerebellum was measured to 5-7 $\mathrm{mV}$ in two experiments [this value is in agreement with that of Margrie et al. (2002), who used a similar K-gluconate-based solution in vivo] but was not compensated for in the displays. The steps to measure the junction potential were (1) place a recording electrode approximately $0.5 \mathrm{~mm}$ above the surface of the cerebellar cortex, (2) replace the paraffin oil covering the brain with the electrode solution (note that the earth electrodes were placed in the neck muscles and hence not in contact with the electrode solution), and (3) measure the difference in DC potential between the electrode solution and the EC environment by moving the electrode a few millimeters down in the cerebellum.

Granule cell recordings were obtained by first lowering the patchclamp electrode under high positive pressure to a location just beneath the first Purkinje cell layer (PCL). The depth of the PCL in the recording area was repeatedly confirmed by EC recordings of Purkinje cells [identified by the coexistence of simple and complex spikes (Ekerot and Jörntell, 2001)] made en passage. Once in the granule cell layer, the high positive pressure was relieved to more moderate levels, and the electrode was slowly advanced until a substantial increase in tip resistance occurred. At that point, a hyperpolarizing current of $0.1-0.9 \mathrm{nA}$ and a negative pressure was applied to establish a gigaohm seal $(0.5-10 \mathrm{G} \Omega$ ) between the electrode and the recorded cell. Once established, brief increases in negative pressure were used to break the seal and gain contact with the interior of the cell. All analysis performed in this study, except when stated otherwise, was made in granule cells that were prevented from firing spontaneously by using mild hyperpolarizing currents of 0.01-0.10 nA. The amount of bias current needed to prevent cells from

\section{Table 1. Basic electrical properties and peripheral input in granule cells}

\begin{tabular}{lc}
\hline Basic membrane responses at -60 to $-50 \mathrm{mV}(n=13)^{a}$ & \\
$\quad$ Input resistance & $602 \pm 183 \mathrm{M} \Omega$ \\
$\quad$ Time constant & $2.3 \pm 0.36 \mathrm{~ms}$ \\
Properties of unitary EPSPs at -70 to $-60 \mathrm{mV}(n=11)^{b}$ & \\
$\quad$ Amplitude of maximal EPSPs & $8.7 \pm 2.1 \mathrm{mV}$ \\
$\quad$ Time-to-peak & $0.95 \pm 0.17 \mathrm{~ms}$ \\
$\quad$ Half decay time & $5.5 \pm 1.7 \mathrm{~ms}$ \\
Coefficient of variation for unitary EPSPs, evoked and spontaneous & \\
$\quad(n=8)^{c}$ & $10.7 \pm 2.9 \%$
\end{tabular}

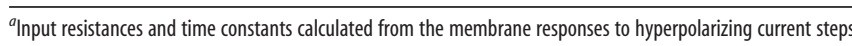
with a duration of $300-1000 \mathrm{~ms}$.

${ }^{b}$ EPSP properties were calculated on 30-200 spontaneous EPSPs from 11 different cells.

The coefficient of variation (CV $=$ SD/mean of the EPSP amplitude) was calculated from EPSPs in the largest, distinct EPSP amplitude group in four cells (at least 30 EPSPS) and from the EPSPs evoked from just suprathreshold mossy fiber stimulation in four cells (at least 16 evoked EPSPs, failures excluded). The CV values were similar and therefore pooled.

firing spontaneously, the maximal EPSP amplitudes, and the amplitudes of occasional evoked spikes were monitored continuously to check the quality of the recording. Any substantial deviations from the maximal values for the neuron and the normal values for the population were taken as a sign of poor recording conditions, and such neurons/periods were excluded from the analysis. For example, if bias currents needed to control a cell exceeded $0.10 \mathrm{nA}$, spike amplitude and time course often looked abnormal, and such cells were immediately discarded. In general, the difficulties consisted of establishing a high seal and making a controlled break-in. If these stages were successful, they resulted very often in high-quality recordings, and $<10 \%$ of these recordings had to be discarded. As the recordings approached an end, they could either terminate suddenly and completely or there would be a sudden reduction in quality associated with a depolarization and change in spike appearance. Such periods were also excluded from analysis.

EC recordings in the cell-attached mode were made with the same type of patch-clamp electrodes using a light suction to improve the isolation of the unit. A few EC recordings from mossy fiber terminals were made with fine tungsten-in-glass electrodes (exposed tip, 3-5 $\mu \mathrm{m}$ ) as described previously (Garwicz et al., 1998; Ekerot and Jörntell, 2001).

To construct peristimulus histograms of activity evoked from the skin during manual stimulation, we used a strain-gauge device mounted on the index finger of the investigator (Jörntell and Ekerot, 2002, 2003). The signal of the strain-gauge device was used mainly as a trigger signal and as a general indication that approximately the same amount of force was applied during stimulations. For each recorded unit with cutaneous input, we attempted to identify the submodality of the input. Units responding to bending of hairs and air puffs from the mouth of the investigator were classified as hair units, whereas units not responding to such stimulation but still firing vigorously on light skin touch were classified as non-hair cutaneous units.

Analysis of EPSPs and IPSPs. All analyses of synaptic inputs were made at a membrane potential of approximately $-70 \mathrm{mV}$, except where stated otherwise. Identification of EPSP-like events and measurements of their peak amplitudes were made semiautomatically using home-made software: the software found and displayed an event, and the user accepted/ rejected it and identified its peak amplitude. This semiautomatic procedure was checked manually to accurately find $99-100 \%$ of all EPSPs that exceeded $1.3 \mathrm{mV}$ in peak amplitude. For the data used in the frequency distribution histograms for spontaneous EPSPs with specific amplitudes, we excluded EPSPs that were preceded by another EPSP of similar or greater amplitude by $<10 \mathrm{~ms}$ because of the risk that repetitive activation could lead to a depression of the synaptic response. To minimize the risk that coincident EPSPs provided a source of error for the measurement of unitary peak amplitudes, the time course of each analyzed EPSP was checked and fitted to the time courses of other EPSPs that had previously been analyzed in the cell. If the time course of an EPSP could not be fitted to those of the other EPSPs with similar amplitude, that event was rejected. Note that the very fast rise times of the EPSPs (Table 1) made it possible to determine the peak amplitudes also on the decay phases of other EPSPs, because the baseline slope was much slower in comparison. 
In such cases, the EPSP amplitude was measured between the starting point and the peak amplitude of the EPSP.

The experimental procedures were approved in advance by the local Swedish Animal Research Ethics Committee.

\section{Results}

In the forelimb area of the cerebellar C3 zone, we made intracellular recordings from 43 granule cells, all of which were scanned for somatosensory input from the ipsilateral forelimb. Twelve of these cells were morphologically identified after successful histological recovery after staining with biocytin or neurobiotin (Fig. 1). Another 20 granule cells were stained after EC recording (see below). Of the 32 stained granule cells, 24 had four dendrites per dendritic endings ("claws"), four had three dendritic endings, and four had five dendritic endings. Other recordings were identified as granule cells by their high input resistance (Table 1) and by their lack of excitatory responses to climbing fiber and parallel fiber activation. Note that the values of input resistances and membrane time constants ( $\mathrm{Ta}$ ble 1) are substantially lower than those of Chadderton et al. (2004), which could be explained by (1) a higher background activity in mossy fibers caused by the absence of anesthesia in our preparation and (2) the fact that we used more mature animals in which the tonic inhibitory activity would be expected to be stronger (Brickley et al., 1996; Wall and Usowicz, 1997). In addition, granule cells were characterized by very large spontaneous EPSPs and a lack of sizeable fast IPSPs.

To analyze individual mossy fiber EPSPs during peripheral stimulation, it was important to evaluate how constant the peak amplitudes of single mossy fiber inputs were. To this end, we used threshold stimulation with a metal microelectrode placed in the granule layer/white matter of an adjacent folium (transfolial). The stimulating microelectrode was sagittally aligned with the recording microelectrode, and in the beginning of the experiment, it was verified that stimulation evoked local field potentials in the recording area. In line with previous in vitro studies (Silver et al., 1992, 1996; D’Angelo et al., 1995; Brickley et al., 2001), we found that the peak amplitudes of unitary mossy fiber EPSPs evoked by electrical stimulation had a low variability (Fig. $1 A, B$; Table $1)$. Note that mossy fiber EPSCs in vitro have been shown to be multiquantal and consecutive responses vary in amplitude in discrete steps when recorded at room temperature (Wall and Usowicz, 1998).
A

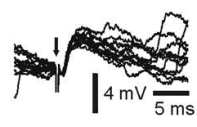

E

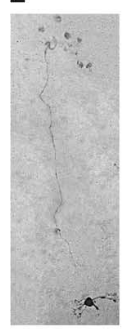

F

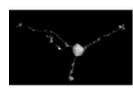

G

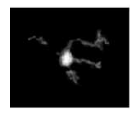

$\mathrm{H}$

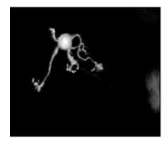

I

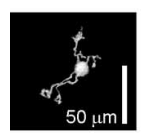

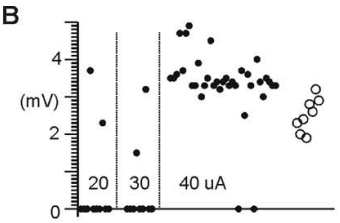

C

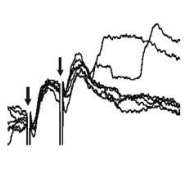

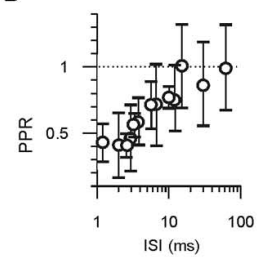
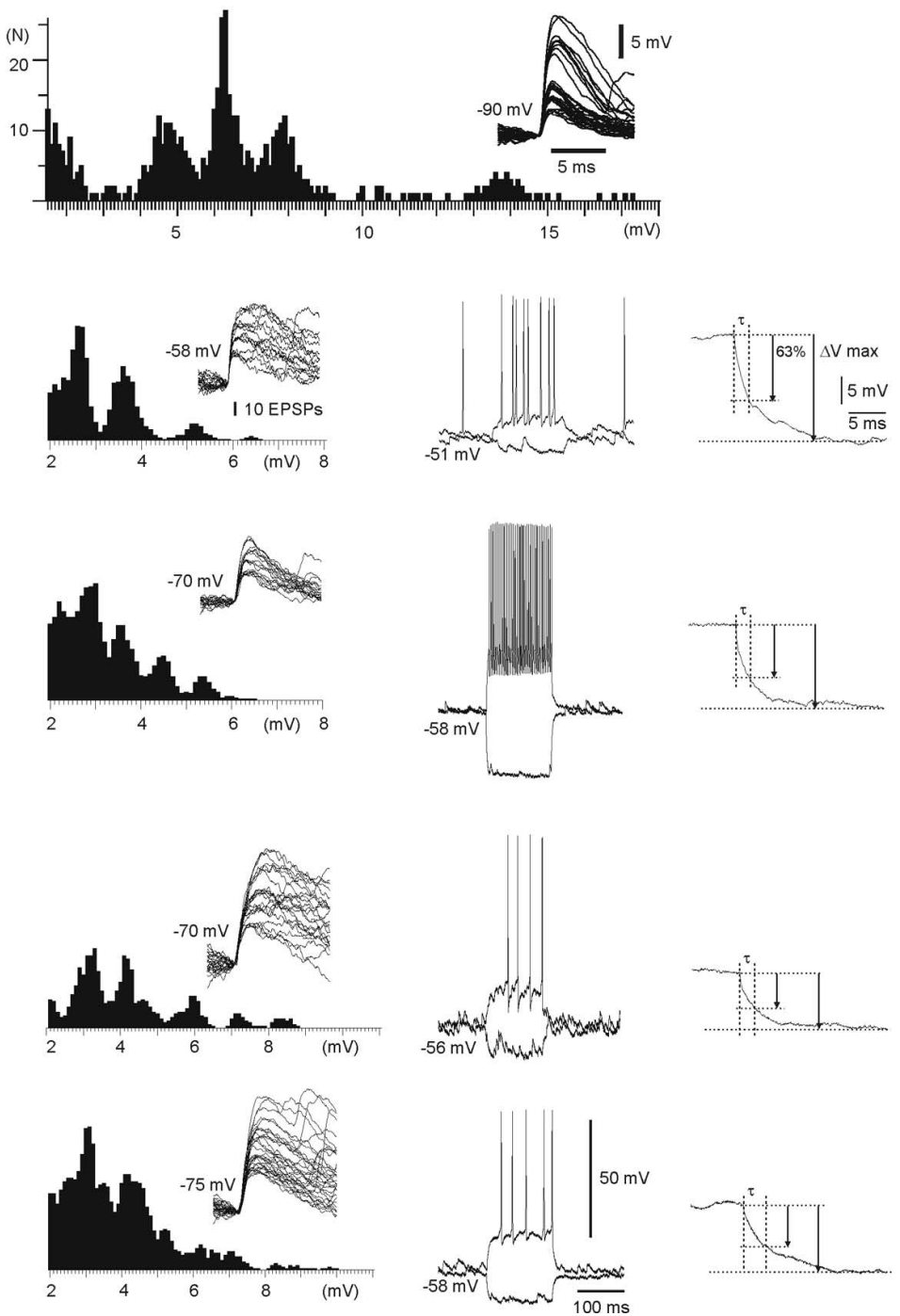

Figure 1. Basic properties of excitatory synaptic inputs and morphological identification. $\boldsymbol{A}$, Overlay of EPSPs evoked by just suprathreshold mossy fiber stimulation (arrow). Calibrations apply to $\boldsymbol{A}$ and $\boldsymbol{C}$. $\boldsymbol{B}$, Responses evoked at subthreshold and suprathreshold stimulation intensities. EPSPs evoked at suprathreshold intensities ( $40 \mu \mathrm{A}$; solid circles) had a coefficient of variation of 14.5\%. Open circles represent peak amplitudes of evoked EPSPs that were preceded (by $\leq 6 \mathrm{~ms}$ ) by a spontaneous EPSP within the same amplitude range as the normal evoked EPSP (2.5-4.2 mV). Apart from these responses, all responses are shown in sequential order. C, Overlay of EPSPs evoked by paired-pulse stimulation with an interstimulus interval of $6 \mathrm{~ms}$. Note that the apparent speeding of the decay phase of the second evoked EPSP primarily appears to be attributable to the fact that it is superimposed on the decay phase of the first evoked EPSP, resulting in a summation of decay phases. This was confirmed to be the case in a simulation of the EPSP responses evoked by paired-pulse stimulation (compare Fig. 6 below). D, Summary plot of all paired-pulse stimulations of mossy fiber-EPSPs (in 8 cells). The second evoked EPSP is plotted as the peak amplitude ratio (mean \pm SD) relative to the first evoked EPSP. Just suprathreshold intensities were used. ISI, Interstimulus interval; PPR, paired-pulse ratio. E, Amplitude frequency histogram for spontaneous EPSPs in one cell. The coefficient of variation for EPSPs with peak amplitudes of 10.4-17.3 $\mathrm{mV}$ was $11.3 \%$. The cell was stained with biocytin, and morphological reconstruction showed that this cell had four dendrites. Inset, Superimposed EPSPs with different amplitudes. Calibrations apply to $\boldsymbol{F}-\boldsymbol{I}$. $\boldsymbol{F}-\boldsymbol{I}$, Similar display as in $\boldsymbol{E}$, but for four other granule cells stained with neurobiotin and reconstructed under the confocal microscope. Membrane responses to depolarizing and hyperpolarizing rectangular current steps are also shown for each of these cells when recorded at 0 bias current (calibrations in $I$ ). Current intensities in $\mathbf{F}-\boldsymbol{I}$ are $20,54,24$, and 32 pA, respectively. The insets at the far right show initial parts of the averaged membrane response to hyperpolarizing rectangular current steps for each cell as well as the method for calculating the time constant $(\tau)$. In $\boldsymbol{F}$, a current step of $-50 \mathrm{pA}$ is used in the far right panel. 
A

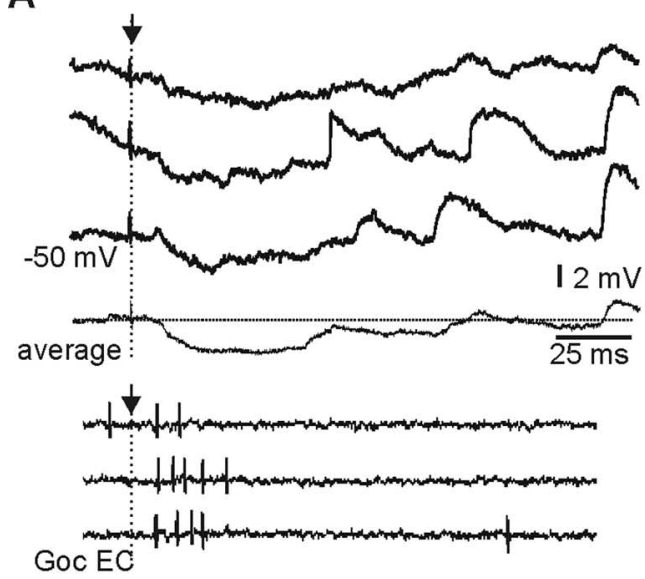

B

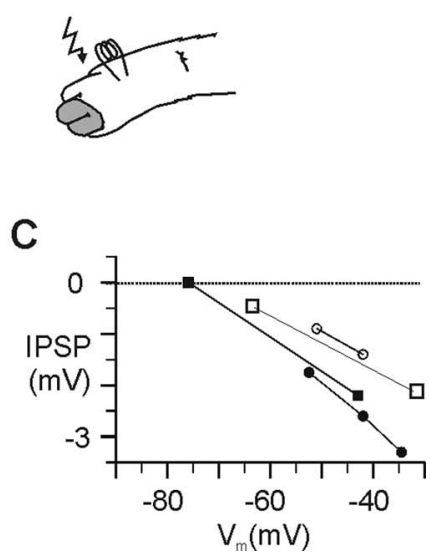

Figure 2. Properties of inhibitory responses. $\boldsymbol{A}$, Responses evoked by electrical skin stimulation in an intracellular granule cell recording ( 3 raw traces and 1 averaged trace) and in an EC recording from a Golgi cell (GocEC). Golgi cells were identified as detailed in Results (see Properties of cell-attached recordings). $\boldsymbol{B}$, Location of electrical skin stimulation in relationship to the receptive field of the granule cell in $\boldsymbol{A}$. C, Peak amplitudes of inhibitory responses plotted against membrane potential for three different cells. SDs (in the order of $10-20 \%$ of the averaged values) were not plotted because of relatively few data points (3-9) for each value.

citatory responses were not evoked (Fig. $2 A, B)$. However, such stimulation failed to evoke substantial fast IPSPs (defined as hyperpolarizing potentials of $>1.0 \mathrm{mV}$ and time-to-peak $<5 \mathrm{~ms}$ ), even though the averaged response proved to contain an IPSP with a slow time course and the Golgi cells within this area typically responded to such stimulation (Fig. $2 A$ ). The peak amplitude of averaged inhibitory responses evoked by electrical skin stimulation varied with the membrane potential, seemingly in a linear manner with a reversal potential approximately $-75 \mathrm{mV}$ (Fig. 2C). Note that the low amplitudes of fast IPSPs were probably not attributable to our recording conditions, because we under the same conditions have recorded sizeable fast IPSPs in stellate and basket cells at rest (Jörntell and Ekerot, 2003). The discrepancy with the data of Chadderton et al. (2004) on this point could be as a result of the absence of

Thus, the variability in the number of quanta released seems to be lower in our in vivo preparation. Both spontaneous and evoked EPSPs had fast rise times and large peak amplitudes (Fig. 1, Table 1). Paired stimulation at short interstimulus intervals resulted in a substantial depression of the second evoked EPSP (Fig. 1C,D). The average maximal depression $(63 \%)$ was remarkably similar to values obtained in vitro (Xu-Friedman and Regehr, 2003), but the average time constant of the recovery, calculated from our pooled data, was much faster in vivo (8 ms compared with $35 \mathrm{~ms}$ in vitro).

In granule cells in which spontaneous activity was recorded for a sufficient amount of time ( $\geq 200 \mathrm{~s} ; n=16)$, we tested whether the frequency distribution histograms of EPSP amplitudes could reveal individual mossy fiber inputs. We found that such histograms were always characterized by three to five peaks, but the amount of separation between peaks varied. Examples of cells in which the population of EPSP amplitudes was distinctly separated into groups are shown for granule cells with four dendrites (Fig. $1 E-G$ ) and for one granule cell with five dendrites (Fig. $1 H$ ). In addition, an example of a granule with less clear separation of EPSP amplitudes is shown in Figure $1 I$. In Figure $1 E$, hyperpolarization down to $-90 \mathrm{mV}$ was used to increase EPSP amplitudes and hence amplify the separation. In other cases, the cells were held at approximately $-70 \mathrm{mV}$. In all cases, there was a group of small spontaneous EPSP-like events of unclear nature with amplitudes just above detection level. Within this group, we sometimes found EPSPs with a distinctly slower time course (see Fig. 7A), which has also been found for granule cell EPSCs in vitro, where they have been attributed to spillover activation of AMPA receptors (DiGregorio et al., 2002). At low intensities, the spike responses to rectangular current pulses varied with the spontaneous EPSPs activity, but stronger current pulses elicited intense, regular spike trains with little sign of adaptation (Fig. $1 F-I$ ).

Another conspicuous feature of granule cell recordings was a lack of substantial fast IPSPs at resting potential $(-60$ to -50 $\mathrm{mV}$ ) and when the cells were depolarized (up to $-20 \mathrm{mV}$ ) with a positive bias current. The most prominent inhibitory responses were observed on stimulation of skin areas in the vicinity of the excitatory receptive field of surrounding granule cells, where ex- anesthesia in our preparation or to the differences in age (our animals were adult, whereas Chadderton et al. used 18- to 27-dold rats). The relative lack of fast IPSPs in our preparation do, however, clearly not contradict findings from a series of in vitro studies, in which it has been suggested that the role of Golgi cell inhibition in granule cells is to set the excitability level on a longer time scale using a predominantly tonic form of inhibition (Brickley et al., 1996; Wall and Usowicz, 1997; Rossi and Hamann, 1998; Hamann et al., 2002).

\section{Granule cells had different types of peripheral input}

Once a granule cell recording was established, the peripheral activation of the spike was investigated qualitatively by manual stimulation to determine to what extent it was activated by cutaneous and joint movement-related input on the forelimb. In line with the known pathways of mossy fiber input to this area of the cerebellar cortex, we found granule cells to be of four types: cutanoeusly activated, strongly activated by joint movement, moderately/weakly activated by joint movements, or not activated from the periphery. For reasons discussed later, the inputs to the activated cells are likely to be from the exteroceptive cuneocerebellar tract (E-CCT), the proprioceptive component of the cuneocerebellar tract (P-CCT), and the LRN. Cells that could not be driven probably received mossy fiber input from pontine nuclei (Brodal and Bjaalie, 1992; King et al., 1998) normally driven by the cerebral cortex, a connection that was transected by the decerebration.

Granule cells with cutaneous input were the most common type. Figure 3, $A$ and $B$, illustrates the responsiveness to cutaneous stimulation of a mossy fiber and a granule cell, respectively, in EC recordings. The raw data and the histograms of spike activation on repeated stimulation illustrate a low spontaneous activity and extremely strong responses on peripheral activation, which were characteristic for mossy fibers (Garwicz et al., 1998) and granule cells with this type of input. Figure 3 also illustrates the general differences in background and evoked synaptic activity between granule cells with different types of input. Generally, strong peripheral activation was associated with low spontaneous activity and vice versa. Strong peripheral activation was also associated with large shifts in the membrane potential produced 
when EPSPs occurring at high frequencies summated, whereas weaker responses produced a less marked shift in membrane potential. In cells with no input, but with spontaneous spike firing (Fig. $3 F$ ), underlying spontaneous depolarizations caused by spontaneous coincidences of background EPSP activity appeared to be responsible for the spike firing.

\section{Cutaneous receptive fields}

Because of the virtual absence of spontaneous activity and the extreme intensity of the evoked responses, the cutaneous receptive field for spike activation was readily delineated. These receptive fields were similar to those reported previously for mossy fiber terminals (Garwicz et al., 1998 ) with respect to size and location on the skin (Fig. 4A). Just like in mossy fibers, a sensitivity gradient within the receptive field [defined by the presence of skin areas within the receptive field from which $<70 \%$ of the maximal response was evoked (compare Fig. $4 \mathrm{~B}$ )] was sometimes observed also in granule cells. To quantify the receptive field for EPSPs, cells were hyperpolarized down to $-70 \mathrm{mV}$ to prevent spiking. Input was tested from several small skin areas, in turn, by using repeated brief, light strokes. A strain gauge mounted on the fingertip of the investigator was used to obtain data on stimulus onset and duration and to control that the force applied to the different skin areas did not differ substantially (Fig. $4 B, D$ ). The peristimulus histograms (Fig. 4C) and the integrated synaptic responses (Fig. 4D) indicated that EPSPs could be evoked from one small skin area only. To quantify this observation, we compared the average net integrated synaptic response evoked from within the receptive field and from adjacent skin areas located outside the receptive field (Fig. 4D). Adjacent skin sites were located on either side of the receptive field, either along the proximo-distal or the radio-ulnar axis.

\section{Analysis of peripheral activation of individual EPSPs}

In cutaneously activated granule cells, the initial part of the response evoked by electrical skin stimulation in the center of the receptive field consisted of a near instantaneous depolarizing step of 15-25 mV (from $-70 \mathrm{mV}$ ) (Figs. 5-7) (i.e., severalfold larger than the maximal amplitudes of the unitary EPSPs) (Table 1). These responses always had a constant response onset latency time of 6-8 ms, identifying the afferent pathway as the E-CCT (Cooke et al., 1971). Weaker responses being composed of only one unitary EPSP could sometimes be evoked from the outskirts of the receptive field (Fig. 5B), with longer, yet constant, response latencies.

Figure 6 illustrates additional examination of the composition
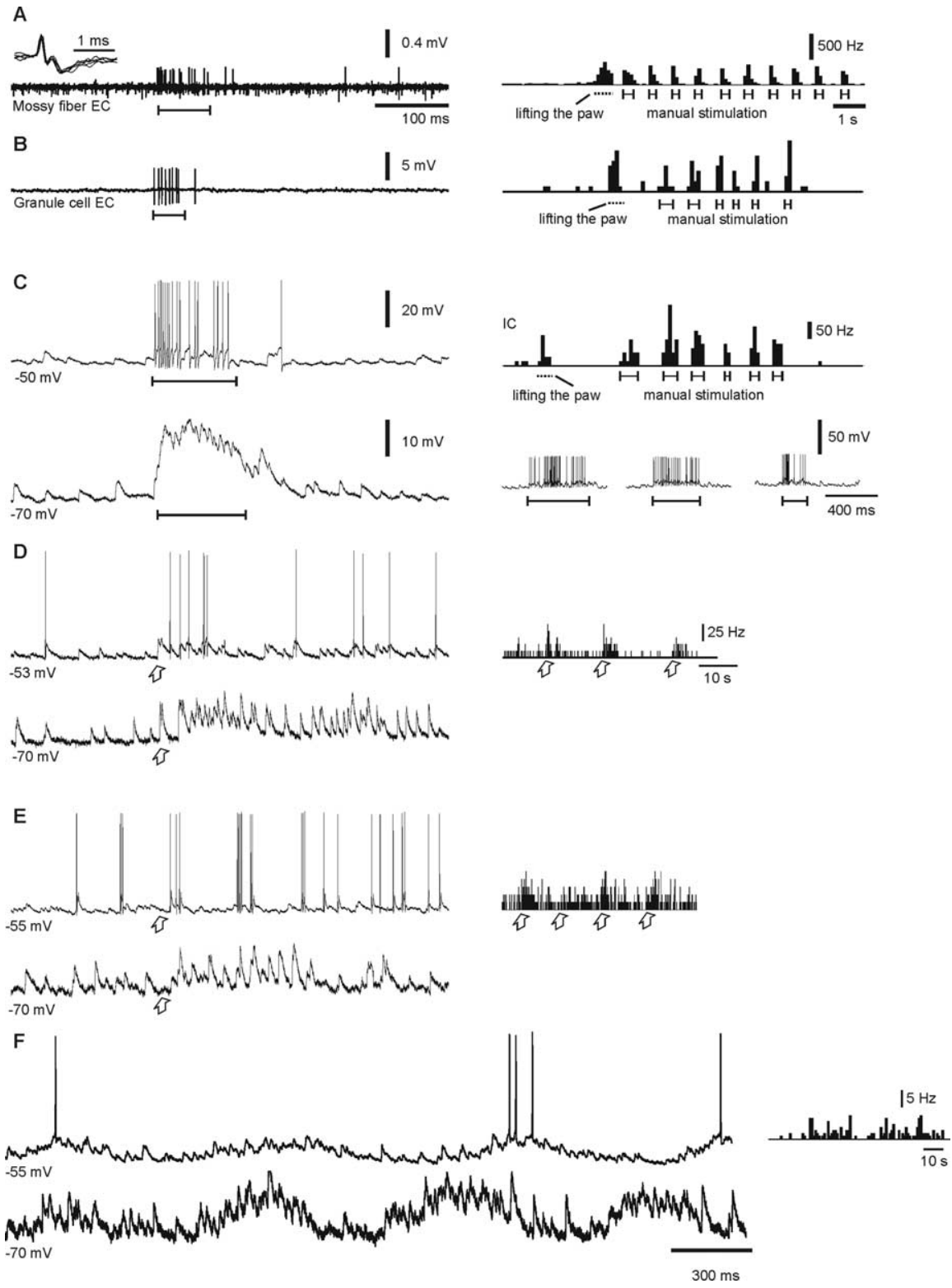

Figure 3. Activity in granule cells with different types of peripheral input. $\boldsymbol{A}$, Raw sweep and histogram of spike activity during manual cutaneous stimulation (indicated by capped lines) for EC recording from mossy fiber terminal with a fine-metal electrode. Note the negative field potential that follows the spike (inset) that represents the synaptic field potential of the mossy fiber terminal (Walsh et al., 1974; van Kan et al., 1993; Garwicz et al., 1998). The time scale applies to all raw traces in $\boldsymbol{A}-\boldsymbol{E}$. Bin width in histograms, $100 \mathrm{~ms}$; the time scale applies to histograms in $\boldsymbol{A}-\boldsymbol{C}$. $\boldsymbol{B}$. Display as in $\boldsymbol{A}$, but from an EC granule cell recording in the cell-attached mode. $\boldsymbol{C}$, Display as in $\boldsymbol{B}$, but for an intracellular granule cell recording at $0 \mathrm{pA}$ bias current (top) and at $-70 \mathrm{mV}$ (bottom). In the bottom right inset, three different raw traces of spike responses to manual stimulations of different durations are shown. $\boldsymbol{D}$, Display as in $\boldsymbol{C}$ for a granule cell with strong activation on joint movement, the onset of which is indicated by empty arrows. The stimulation lasted for the remainder of the displayed sweep. Note the much longer time scale of the histogram in $\boldsymbol{D}$. All calibrations apply to $\boldsymbol{D}$ and $\boldsymbol{E}$. $\boldsymbol{E}$, Display as in $\boldsymbol{D}$ for a granule cell with weak activation on joint movement. $\boldsymbol{F}$, Intracellular activity in a granule cell without peripheral activation but with periodic spontaneous spike and EPSP activity.

of responses evoked by electrical skin stimulation. Morphological identification and the frequency distribution of spontaneous EPSP amplitudes indicated that this cell had four dendrites (Fig. $6 A, B)$. Electrical skin stimulation elicited a strong, stereotyped EPSP response (Fig. 6C). We set out to analyze the minimal number of mossy fiber synapses that could underlie the evoked response by first defining a time window within which a simulated response must reach the peak amplitude of the evoked response (Fig. 6D). Averages of EPSPs within the four different groups of amplitudes were used to simulate, by addition, evoked responses 
A
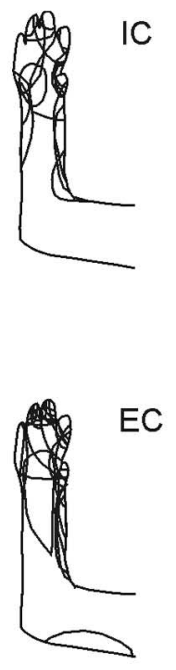

B

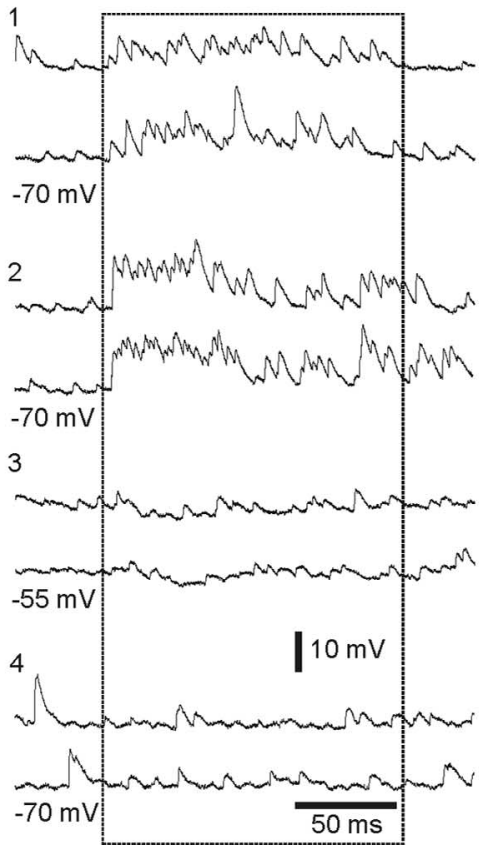

C
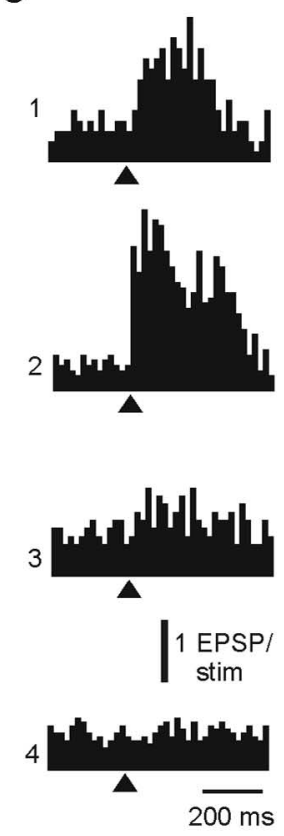

D

Int. synaptic resp.

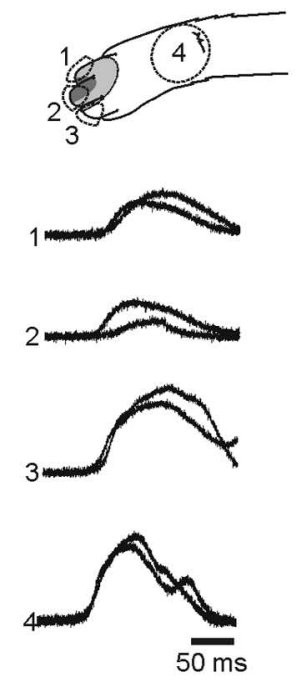

4000 ?

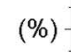

2000

t. strain gauge signal

2000

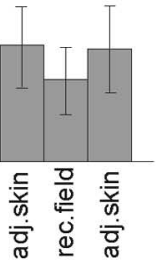

Figure 4. Small receptive fields in granule cells activated from the skin. $A$, Overlaid outlines of granule cell cutaneous receptive fields from intracellular (IC; $n=19)$ and EC $(n=30)$ recordings. $B$, Evoked activity shown in raw sweeps of intracellular activity and peristimulus histograms of EPSPs during manual stimulation at different circumscribed skin sites (1-4). The corresponding strain-gauge signals (see Materials and Methods) are shown on the left (arbitrary units) to illustrate the fact that there was no bias to use higher manual stimulation intensities inside the receptive field (see also D). In the outline of the paw, the receptive field is indicated with 2 degrees of shading to indicate the sensitivity of the specific skin area. Note the slow hyperpolarizing response evoked from site 3 adjacent to the receptive field. C, Peristimulus histograms represent EPSPs evoked by light manual skin stimulation (stim) that was repeated $10-30$ times for each skin site and display -300 to $+500 \mathrm{~ms}$ relative to the onset of the stimulation with a bin width of $20 \mathrm{~ms}$. D. Summarized data from 10 cells with cutaneous input. Net integrated synaptic responses (Int. synaptic resp.) evoked from the receptive field (rec. field) exceeded baseline EPSP activity by nearly 1000\%. The integrated synaptic response from adjacent skin (adj. skin) sites (such as sites 3 and 4 in $B$ ) typically was much lower, whereas no input was evoked from other skin areas. For comparison, the net integrated strain-gauge signals (Int. strain-gauge signal) from these stimulations are shown below. Net integrated signals were calculated by dividing the rectified integrated signal from the first $50 \mathrm{~ms}$ after onset of stimulation with $50 \mathrm{~ms}$ of rectified and integrated prestimulus activity.

A

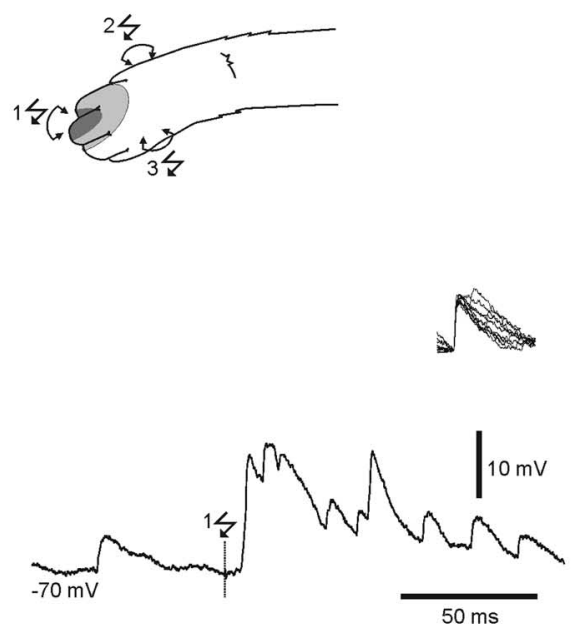

B

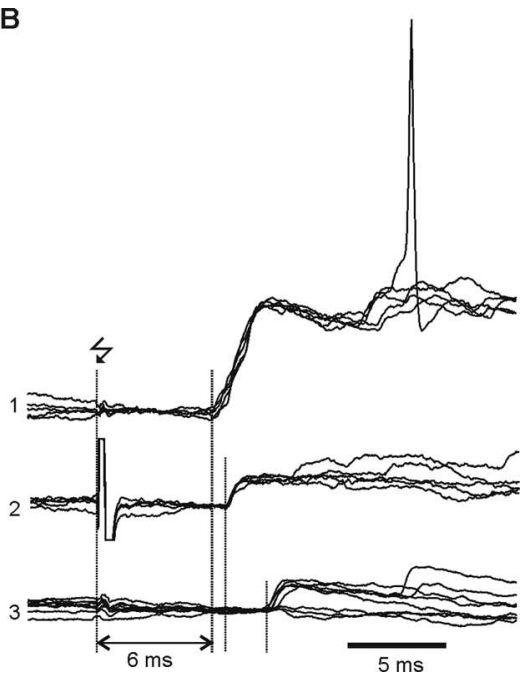

Figure 5. Electrical skin stimulation evokes reproducible, fixed-latency responses. $\boldsymbol{A}$, Electrical skin stimulation within the center of the receptive field evoked a near instantaneous depolarizing step with a peak amplitude that was severalfold larger than the maximal unitary EPSP (inset). B, Superimposed successive responses to electrical skin stimulation delivered to the three skin sites indicated in $A$. Responses evoked outside the receptive field could sometimes lead to the activation of unitary EPSPs, probably through current spread to the outskirt of the receptive field. Note the constant response latency times in each case. The voltage calibration is the same as in $\boldsymbol{A}$.

composed of activity in different mossy fiber afferents (Fig. $6 E-$ $G)$. First, we started with the single EPSP with the largest peak amplitude, but neither 500 nor $1000 \mathrm{~Hz}$ EPSP activation of this afferent came even close of being capable to reproduce the evoked response. We also noted that because of the paired-pulse depres-

sion ratios at $1-3 \mathrm{~ms}$ intervals $(60-63 \%)$, $1 \mathrm{~ms}$ intervals were required for temporal summation to gain additional depolarization during the EPSP train. Therefore, as a next step, we added the activation of other EPSPs (ii-iv) also at $1000 \mathrm{~Hz}$ (Fig. 6G). We found that only when we simulated a near simultaneous activation of all four EPSPs at $1000 \mathrm{~Hz}$ was it possible to reproduce the depolarization observed in the evoked response. It can be noted that a double activation at $1000 \mathrm{~Hz}$ of all four simulated EPSPs was enough to reach the same level as in the evoked response (Fig. 6G, bottom), whereas an additional $1000 \mathrm{~Hz}$ activation made the simulated response "overshoot" its target. In nonsimulated evoked response (Fig. 6D), it is likely that the plateau depolarization obtained is attributable to asynchronous, lowerfrequency activation of the different mossy fiber afferents.

We performed this analysis in six cells in which the evoked responses reached a peak within 3-4 ms after onset. The results indicated that simultaneous activation of $3.51 \pm 0.51$ different mossy fiber afferents was required to reproduce the observed responses. Note that this measure is likely to be conservative, because mossy fibers typically do not respond as intensely as in our simulation on electrical skin stimulation 
A
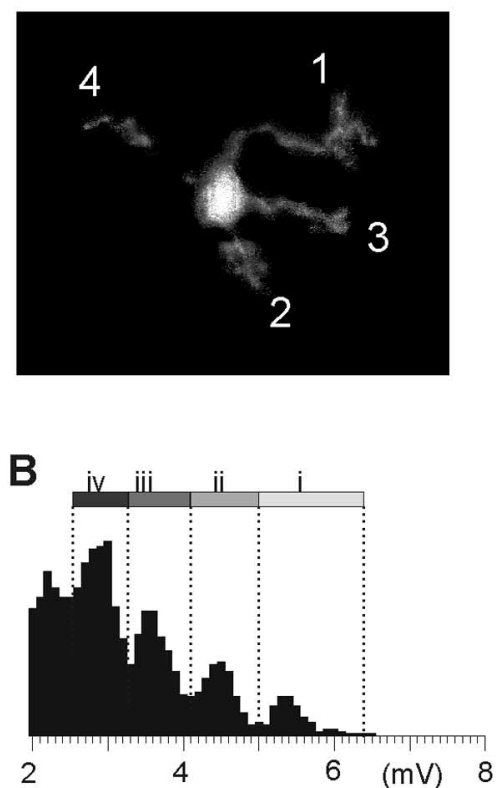

C

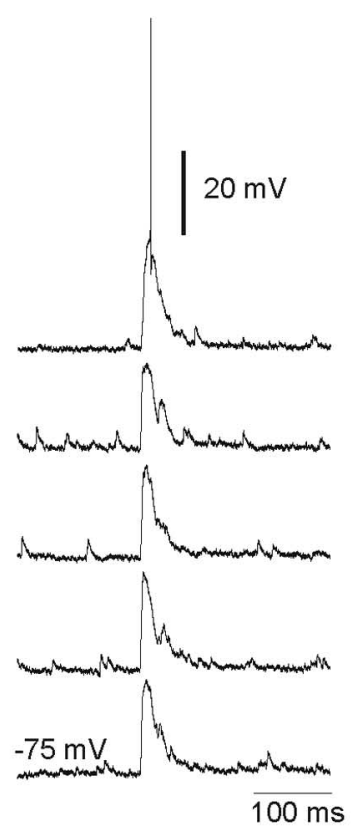

D

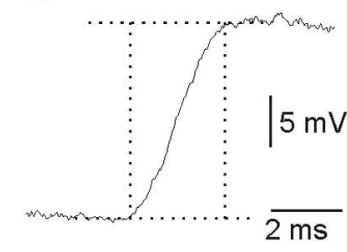

F

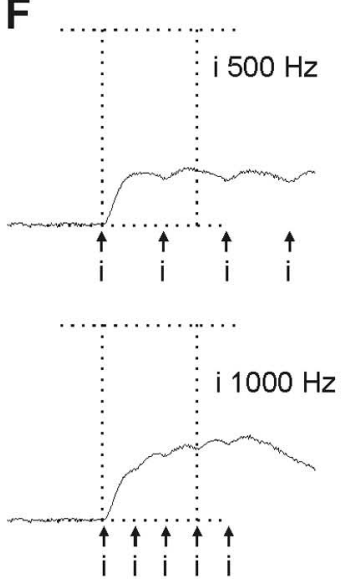

E

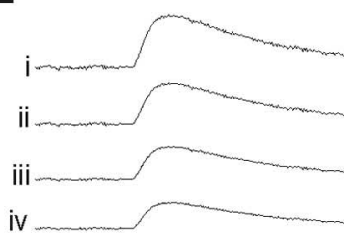

G

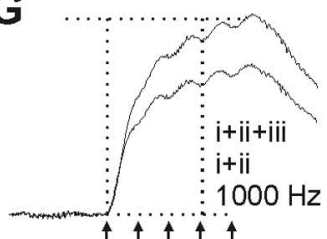

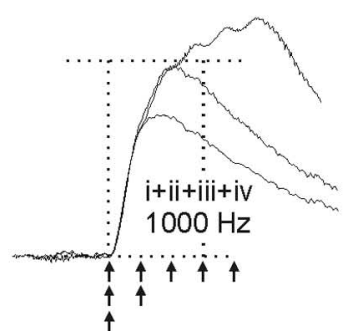

Figure 6. Simulation of the rising phases of responses evoked by skin stimulation. $\boldsymbol{A}$, Morphology of a recorded granule cell with four dendritic endings. $\boldsymbol{B}$, Amplitude frequency distribution histogram of spontaneous EPSPs. Numbers i-iv refer to EPSPs within distinct amplitude groups. $C$, Five consecutive responses evoked by electrical skin stimulation within the receptive field, which was located at the tip of the first digit and at the base of the second digit. The response latency time from stimulation was 6 ms (data not shown). $D$, Sample raw trace of the rising phase of the evoked response. Dotted lines indicate the time window within which all responses peaked. $\boldsymbol{E}$, Averages of spontaneous EPSPs within amplitude groups i-iv. $\boldsymbol{F}$, Simulated responses on repeated activation of an EPSP (i) at 500 and $1000 \mathrm{~Hz}$. Summated responses were calculated with a $60 \%$ depression of the second EPSP compared with the first (compare Fig. $1 D$ ); no additional depression was applied to the succeeding EPSPs. G, Simulated responses with temporal and spatial summation of various number of different EPSPs.

(Garwicz et al., 1998) and because no additional depression beyond the first pair of EPSPs was integrated in the simulation.

In cutaneously activated cells, the first few milliseconds of the evoked responses seemed to be built up of several individual EPSP-like events. The time courses and amplitudes of these events, delineated by inflection points on the time-voltage curve, could be fitted with averages of individual synaptic inputs recorded in the cell (Fig. 7). The derived voltage signal showed that the inflection points used to define the onset times of EPSPs clearly differed from the range of the baseline noise (Fig. 7C). This was always confirmed to be the case when the rising phases were analyzed with respect to EPSP composition. Of special interest were responses in which two or more EPSPs were initiated within $1 \mathrm{~ms}$ of each other, or in which consecutive EPSPs had increasing response amplitudes. In such response phases, the EPSPs had to be caused by activity in different mossy fiber afferents, because mossy fibers do not fire faster than $1000 \mathrm{~Hz}$ in vivo (van Kan et al., 1993; Garwicz et al., 1998) and unitary EPSPs depress substantially when activated repetitively at short intervals (Fig. 1D). In a systematic analysis of EPSP-like events in the rising phases of the evoked responses, we combined these two criteria to obtain an estimate of the theoretically minimal number of individual synapses activated in the initial $5 \mathrm{~ms}$ of responses evoked by electrical or manual stimulation. This analysis was performed for 10-20 consecutive responses in all 10 cells in which we obtained a sufficient amount of responses recorded at approximately $-70 \mathrm{mV}$. We found that the initial part of the response contained $3.2 \pm 0.64$ EPSPs (range, $2-4$ ). A total of $2.6 \pm 0.71$ of these (range, 1-4) had to be attributable to the activity in different mossy fiber synapses, because they occurred at higher rates than $1000 \mathrm{~Hz}$ or because consecutive EPSPs had increasing amplitude.

\section{Granule cells with noncutaneous input}

Within the group of granule cells with deep input, cells activated from individual digits or the wrist joint typically had strong responses and therefore probably received their input from the P-CCT (Cooke et al., 1971). Among the cells that were activated from the elbow or shoulder joints, some responded much less distinctly and faithfully than others and were, in some cases, only activated by squeezing of deep structures. Their peripheral activation was similar to that found for cells in the LRN (Oscarsson and Rosén, 1966; Clendenin et al., 1974), and when tested ( $n=$ 10), these cells were also found to be activated by electrical stimulation in the LRN. Granule cells with noncutaneous input were spontaneously active (Fig. 2, Table 2). However, the onset of the response was less intense than in cutaneously activated granule cells. For example, the net integrated synaptic responses were only a little more than double the background activity (Table 3 ). The analysis performed for cutaneously activated granule cells was hence not possible. Nevertheless, during stimulation by appropriate joint movements, we found that EPSPs of all amplitudes were driven by the same type of input. This is shown as examples for one cell with strong activation and for another cell with weaker, less direct activation on joint movement (Fig. 8). In the cell with strong activation, we used a weaker, long-lasting stimulation to obtain a low level of tonic activation during which the amplitudes of individual EPSPs were relatively unperturbed (Fig. 8C). Using stronger stimulation, the initial part of the response was a strong phasic response with EPSP summation cre- 
A

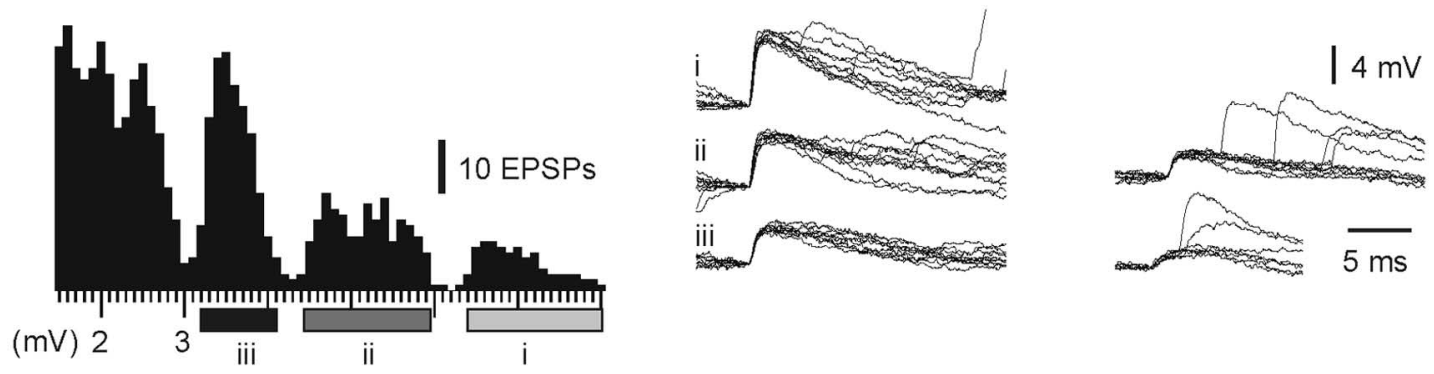

B

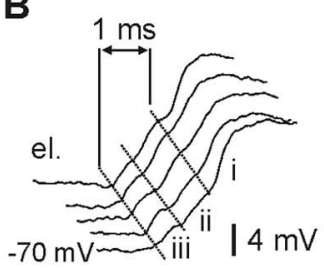

C

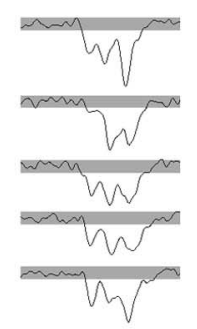

D
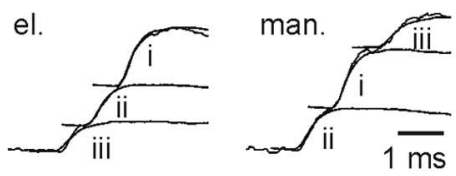

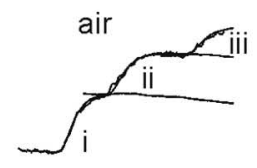

E

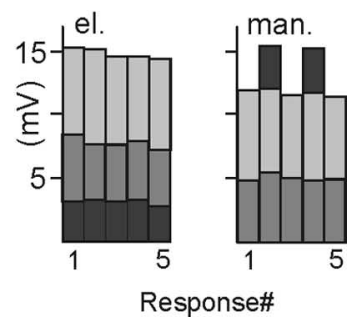

Figure 7. The rising phase of evoked responses is composed of different EPSPS. A, Amplitude frequency histogram for spontaneous EPSPs and superimposed raw traces of EPSPs from amplitude groups $\mathrm{i}$-iii as well as smaller EPSPs of fast and slow types. $\boldsymbol{B}$, Close-up of rising phases of responses evoked by electrical stimulation. Diagonal lines connect the approximate starting points for individual EPSPs. The response latency time from the periphery was $6-7 \mathrm{~ms}$ in all cases (data not shown). Calibrations apply to $\boldsymbol{B}$ and $\boldsymbol{D}$. $\boldsymbol{C}$, The derived signal from the traces in $\boldsymbol{B}$. The gray area shows the range of the baseline noise. $\boldsymbol{D}$, Individual averaged spontaneous EPSPs from amplitude groups i-iii could be used to reconstruct the rising phases of evoked responses evoked by electrical, manual, and air-puff stimulation within the receptive field. $\boldsymbol{E}$, For five responses each, the recruitment order of EPSPs in evoked responses is shown for electrical (el.) and manual (man.) skin stimulation. The first evoked EPSP of each response is shown at the bottom of the graph, and the last is shown at the top. The correspondence between the amplitude of the evoked EPSPs and those of the amplitude frequency histogram in $A$ is indicated by shading of the bars.

Table 2. Spontaneous activity in cells with different input

\begin{tabular}{llcl}
\hline & EC spike (Hz) & IC spike (Hz) & EPSPs \\
\hline Cutaneous & $0 \pm 0(n=29)$ & $0 \pm 0(n=6)$ & $10-30(n=14)$ \\
Strongly/moderate joint movement input & $6 \pm 3(n=8)$ & $5 \pm 1(n=3)$ & $20-50(n=6)$ \\
Weakly activated/unaffected & $8 \pm 7(n=10)$ & $10 \pm 9(n=4)$ & $20-100(n=7)$ \\
\hline
\end{tabular}

Table 3. Evoked activity in granule cells with specific input (mean \pm SD)

\begin{tabular}{llll}
\hline & EC spike $(\mathrm{Hz})$ & IC spike $(\mathrm{Hz})$ & Int. syn. response \\
\hline Cutaneous, hair, receptive field & $910 \pm 120(n=10)$ & $920 \pm 95(n=4)$ & \\
Cutaneous, non-hair, receptive field & $620 \pm 210(n=5)$ & $550(n=2)$ & \\
Cutaneous, outside receptive field & & & \\
$\quad$ Adjacent site 1 & $0(n=5)$ & $0(n=5)$ & \\
$\quad$ Adjacent site 2 & $0(n=5)$ & $0(n=5)$ & \\
Strongly/moderate joint movement input & $130 \pm 90(n=6)$ & $210 \pm 80(n=3)$ & $340 \pm 190 \%(n=4)$ \\
Weakly activated with long response latency times & $44 \pm 19(n=4)$ & $48 \pm 17(n=3)$ & $230 \pm 50 \%(n=3)$
\end{tabular}

Firing activity recorded at $0 \mathrm{pA}$, spontaneous EPSP activity recorded at approximately $-70 \mathrm{mV} .^{\prime} 0 \mathrm{~Hz}$ ' indicates that the cells had a spontaneous rate of $<0.4$ $\mathrm{Hz}$. All spike frequencies were calculated as the number of spikes divided by the time window within which they occurred. The start point of the time window was defined as halfway between the first included spike and the nearest preceding spike. The end point of the time window was defined as the time point halfway between the last included spike and the nearest subsequent spike. Spike frequencies in evoked responses were calculated on at least three consecutive spikes (typically 5-15), whereas spontaneous activity represent averages over $\geq 30 \mathrm{~s}$. The rectified, integrated synaptic responses (Int. syn. response) were calculated as described in Fig. 4

ating a depolarizing shift in the membrane potential (Fig. $8 \mathrm{~A}$ ). Such shifts in membrane potential were observed also in other cells with strong activation by joint movements. The amplitude of the DC shift exceeded the peak amplitude of the maximal unitary EPSP $(6-7 \mathrm{mV})$ by $58 \pm 11 \%$ (mean $\pm \mathrm{SD} ; n=5$ ) and could therefore not be attributable to the activation of a single EPSP only. (For comparison, in cells with cutaneous input, the DC shift exceeded the maximal unitary EPSP amplitude by $204 \pm 24 \%(n=6)$. In a cell with weaker, indirect activation on elbow extension, peristimulus histograms showed that all EPSPs, as defined in the amplitude frequency histogram, were driven by this input (Fig. 8D-F).
Properties of cell-attached recordings In addition to the intracellular recordings, we made 65 EC granule cell recordings using the cell-attached recording mode. Twenty of the EC recordings were morphologically identified as granule cells using the juxtacellular labeling technique (Pinault, 1996). Apart from the absence of spike responses to inferior olivary stimulation, EC granule cell recordings were distinguished from EC Golgi cell recordings by their shorter spike durations [mean $\pm \mathrm{SD}: 0.87 \pm 0.16 \mathrm{~ms}$ for $25 \mathrm{EC}$ granule cell recordings, $1.5 \pm 0.12 \mathrm{~ms}$ for 5 EC Golgi cells; the latter value is in agreement with van Kan et al. (1993)], the much shorter recording distance over which the spike could be followed, and their more irregular spontaneous firing rate (cf. Holtzman et al., 2006). They were also distinguished from mossy fiber recordings by the absence of a "glomerulus potential” (Walsh et al., 1974), their longer spike durations [the duration of EC mossy fiber spikes is $<0.5$ ms (Fig. 2A, inset) (van Kan et al., 1993; Garwicz et al., $1998)$ ], and, in $70 \%$ of the EC recordings, by the observation of small EPSP-like events during some stage of the recording.

Spontaneous and evoked spike activity in granule cells with different inputs

In the total material of IC and EC recorded granule cells, our tests indicated that all 108 cells except two were activated by one type of somatosensory input only. Furthermore, there was a specific 
depth distribution of granule cells depending on the type of input they received (Table 4). Cutaneously activated granule cells were, by far, the most common type. The firing characteristics of these cells were similar to those of mossy fibers of the E-CCT (Garwicz et al., 1998; Ekerot and Jörntell, 2003) in that the spontaneous activity was low, in granule cells zero, but appropriate peripheral activation evoked very strong spike firing throughout the duration of the stimulation (Figs. 2, 9; Table 3). However, the extreme firing frequencies observed is likely to primarily reflect that the manual skin stimulation used is an optimal activation of these inputs. During behavior, these inputs may be used for cutaneous proprioception (see Discussion), which probably will activate the cells in a lower-frequency range. Also, proprioceptive mossy fibers of the LRN (Clendenin et al., 1974) and the P-CCT (Cooke et al., 1971) can fire at $1 \mathrm{kHz}$ under appropriate peripheral activation, but activation under behavior seems to consist in much more moderate firing rates (50$300 \mathrm{~Hz}$ ) (van Kan et al., 1993).

In the majority of cutaneously activated granule cells, we even found a submodality-specific input, because some cells were activated by skin hairs only, whereas others were not activated from hairs at all. Note also that the spontaneous EPSP frequency in granule cells was much higher than the spontaneous spike firing frequency, which at least for cutaneously activated granule cells that lacked spontaneous spike firing directly shows that activation of more than one EPSP was required to fire the cell (Table 2).

We found a general relationship between the activity of spontaneous EPSPs and spontaneous spikes (Table 2), suggesting that the spike activity of granule cells primarily was a reflection of the ongoing synaptic input. To further test this, we first compared the spike activation in granule cells that were phasically activated on brief stimulation of skin hairs. The peristimulus histograms of the evoked responses were remarkably congruent between different granule cells, and the response onset latency times were identical (Fig. 9B). However, mossy fibers carrying this type of information are typically rapidly adapting (Garwicz et al., 1998), and longer-duration stimulations resulted in spike trains with adapting firing frequencies (Fig. 9C). Granule cells with tonic responses to skin stimulation were few, but as can be seen in the example in Figure 9D, these cells responded with sustained spike trains for the duration of the stimulation. Among granule cells activated by joint movements, a tonic response component was more common. Also, in this case, was there a sustained spike firing for the duration of the stimulation, with no obvious consistent temporal pattern after the initial part of the response (Fig. $9 E)$.

\section{Discussion}

In the present study, we investigated the peripheral input in intracellular whole-cell and EC cell-attached granule cell recordings in a nonanesthetized in vivo preparation. In granule cells
B

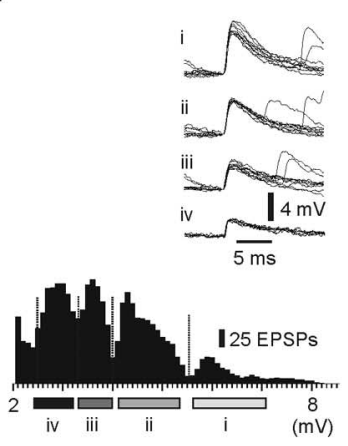

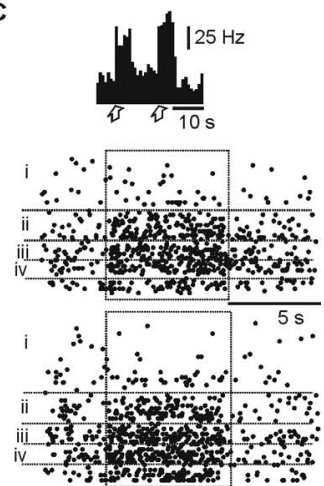

E

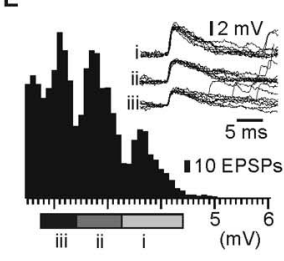

$\mathrm{F}$

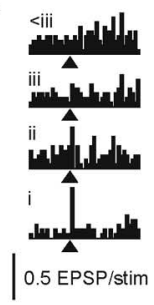

Figure 8. Activation of EPSPs in granule cells driven by joint movement. $\boldsymbol{A}$, Raw traces of EPSP activity during flexion (open (filled arrows) of digit 4 for a cell that was strongly activated by flexion of this digit only. $\boldsymbol{B}$, Amplitude

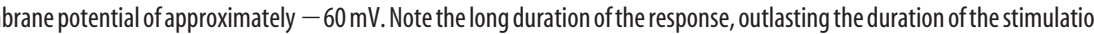

Table 4. Type of input and depth distribution $(n=92)$

\begin{tabular}{lcc}
\hline & Fraction of cells (\%) & Depth of Purkinje cell layer \\
\hline Cutaneous input & 55 & $70 \pm 35 \mathrm{~mm}$ \\
$\quad$ Hair & 21 & \\
Non-hair & 16 & \\
Both/not investigated & 18 & $194 \pm 70 \mathrm{~mm}$ \\
Joint movement input & 25 & \\
One digit or paw & 8 & \\
Elbow and/or shoulder & 9 & \\
Indirect/deep input & 7 & $245 \pm 63$ \\
Inhibition from skin & 2 & \\
No somatosensory input & 18 & \\
Input from skin and joint movement & 2 & \\
\hline
\end{tabular}

The proportion of granule cells activated by specific inputs and their recording depth from the Purkinje cell layer are shown.

activated by skin input, we found that all cutaneous synaptic input was driven from small overlapping receptive fields. In these cells, two different types of analyses each indicated a contribution to the evoked response from at least three or four mossy fiber synapses (i.e., probably all mossy fiber synapses available). We also found that different granule cells were driven by different types of input and that they, overall, had a specific depth distribution depending on the input they received.

\section{Firing properties}

All granule cells had a background of EPSP activity, which is in line with our previous observations in this preparation that all mossy fibers are spontaneously active (Garwicz et al., 1998; Ekerot and Jörntell, 2001) (Fig. 3A). However, some granule cells 
A

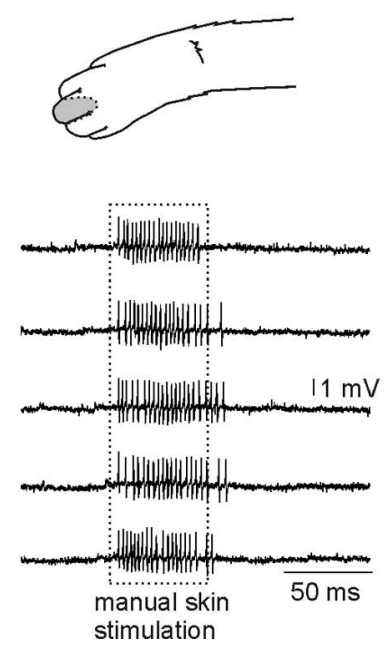

B
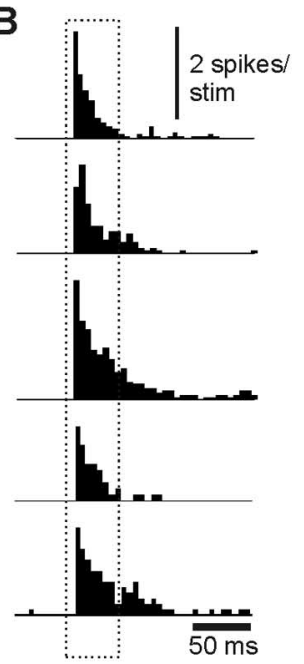

C

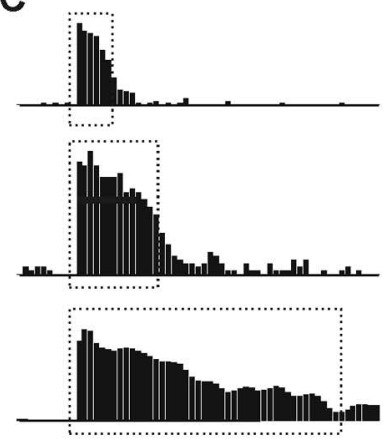

D

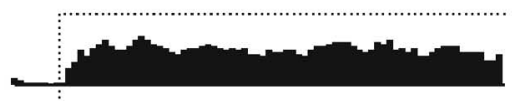

E
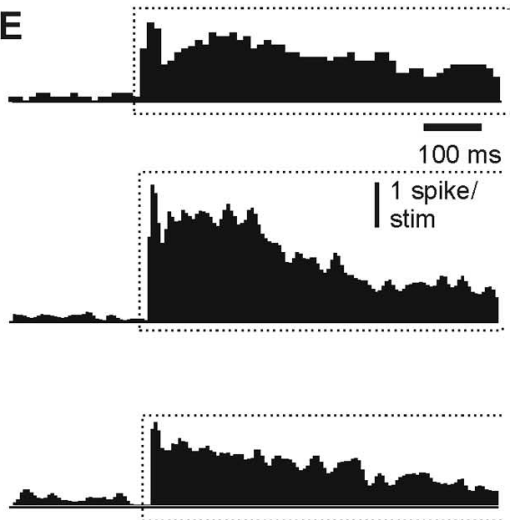

Figure 9. Similar responses in granule cells driven by the same type of input. $\boldsymbol{A}$, Spike responses in an EC recorded granule cell with phasic skin responses to repeated short manual stimulation. The location of the receptive field is shown at the top. The duration of skin stimulation is indicated by the dotted box. $\boldsymbol{B}$, Peristimulus histograms of spike responses in a set of EC recorded granule cells with similar receptive field properties as in $\boldsymbol{A}$. Bin width, $5 \mathrm{~ms}$. The same calibrations apply to $\boldsymbol{B}$ and $\boldsymbol{C}$. $\boldsymbol{C}$, Spike responses to skin stimulations of different durations in a single granule cell. $\boldsymbol{D}$, Response to long-lasting cutaneous stimulations in a granule cell with a tonic input from the skin. Bin width, 10 ms. Calibrations are as in $\boldsymbol{E}$. $\boldsymbol{E}$, Spike responses to maintained joint bending in three granule cells with a tonic response component to joint movement. These cells responded to dorsal flexion of the wrist (2) and palmar flexion of the wrist. Bin width, 10 ms. stim, Stimulation.

did not fire any spontaneous spikes, indicating that a single EPSP is not enough to fire these cells, which was also reported by Chadderton et al. (2004). Overall, there was a correlation between the spontaneous activities of spikes and EPSPs (Table 2), but the spike activity typically was much lower than the EPSP activity, indicating that much of the mossy fiber activity is filtered out. Note that the absence of spontaneous spike activity in many granule cells activated from the skin was probably attributable to the special situation of the preparation, with the animal being completely still. We frequently noted that the cutaneous input was so sensitive that passive movement of the forelimb, without touching the receptive field, was enough to make the cell start firing (Fig. 3B). It is likely that the high sensitivity of the receptors in the hair follicles and/or skin can make them fire even as the skin stretches during joint bending and, in that sense, mediate the function of cutaneous proprioception (cf. Edin and Johansson, 1995; Edin, 2004).

\section{Convergence patterns}

In both intracellular and EC recordings, we found that granule cell spikes were driven by one type of somatosensory input and, in the cells activated by cutaneous input, from one receptive field only and even from one submodality only (hair/non-hair). We found little evidence for convergence of mossy fibers activated by different types of input or mossy fibers activated from different receptive fields (different sites on the skin or different specific joints). This finding did not come as a surprise because there is an orderly zonal-microzonal termination of many mossy fiber tracts. Mossy fibers of the E-CCT have specific receptive fields and are distributed approximately along the longitudinal microzonal organization previously described for climbing fibers with specific cutaneous receptive fields (Ekerot and Larson, 1980; Ekerot et al., 1991; Garwicz et al., 1998). Therefore, granule cells within a microzone are mainly reached by mossy fibers with the same receptive field, and, accordingly, we found that granule cell receptive fields were similar to those previously reported for mossy fiber terminals (Garwicz et al., 1998). It should be emphasized that an absence of integration of different cutaneous inputs in granule cells is strongly supported by the fact that also the cutaneous parallel fiber receptive fields in Purkinje cells and interneurons are similar to those of single mossy fibers (Ekerot and Jörntell, 2001; Jörntell and Ekerot, 2002, 2003).

In addition to the microzonal organization described previously for mossy fiber terminals, we now found that granule cells also had a specific depth distribution depending on the type of input they received (Table 4). These observations suggest a detailed topographical organization within the three-dimensional space of the granule layer that further argues against a convergence of different types of mossy fiber inputs in granule cells.

\section{Peripherally driven synaptic inputs}

In cells with strong responses to skin stimulation or joint movements, evoked responses consisted in a near instantaneous DC shift of $10-25 \mathrm{mV}$ (from $-70 \mathrm{mV}$ in membrane potential) that was sustained by a high-frequency activation of EPSPs. Because of the depression of the EPSP amplitudes at high-frequency activation, only in the initial phase of the response was it possible to use amplitude identification of EPSPs to analyze the contribution of individual mossy fiber afferents. For granule cells with cutaneous input, we made two different types of analyses to obtain a measure of the theoretical minimal number of EPSPs contributing to the evoked response. As shown in Figure 6, by using the average time course of different EPSPs identified in the distribution histograms, a simulation of the initial phase of the response indicated that more than three different mossy fiber afferents firing in near synchrony at nearly $1000 \mathrm{~Hz}$ had to participate in the response. Considering that some granule cells had only three dendrites, this analysis indicated that all available mossy fiber inputs had to participate in the response. The other type of analysis was more conservative in that it included only EPSPs discernible by inflection points in the rising phase of the response, and only if they occurred within $1 \mathrm{~ms}$ of each other or if consecutive EPSPs had increasing amplitudes. Still, this analysis indicated that at least three different afferents contributed to the strong responses evoked in granule cells activated via the E-CCT.

Granule cells not activated via the E-CCT were divided into 
three types: (1) cells strongly activated by joint movements; (2) cells weakly/moderately and/or indirectly activated by joint movements/skin stimulation; and (3) cells with no peripheral input. Because of their activation properties, the driving mossy fiber systems were suggested to be (1) the P-CCT, (2) the LRN, and (3) the parts of the pontine nuclei that normally are driven by pathways from the cerebral cortex but that were deafferented by the brainstem transection of our preparation. For cells strongly activated by joint movements, we could make another type of analysis of the rising phase of the response. The depolarization of this phase exceeded the peak amplitudes of the largest EPSPs by $>50 \%$. This was an indication that at least more than one EPSP had to contribute to the response, because the EPSP of a single afferent could not summate to reach this level of depolarization. We also observed in all cells driven by joint movements that EPSPs of all different amplitudes were driven by the same stimulation (Fig. 8). Importantly, in none of these cells did we observe any cutaneous input of the E-CCT type, even though this was routinely tested for many skin sites both manually and electrically.

\section{Theories of cerebellar granule cell function}

Our results point in the direction that granule cells function as signal-to-noise-enhancing threshold elements with a single, specific type of input. This would be a new model of granule cell function that contrasts with the prevailing models of granule cell function as pattern discriminators/sparse coders or temporal pattern generators, models that have never before been evaluated in actual granule cell recordings.

The concepts of pattern discrimination and sparse coding in granule cells have heavily influenced current models about the function of the cerebellar granule layer (Marr, 1969; Albus, 1971; Tyrrell and Willshaw, 1992; Houk et al., 1996; Schweighofer et al., 1998, 2001; Wolpert et al., 1998; Chadderton et al., 2004; Semyanov et al., 2004). The underlying assumption is that there is a divergent distribution of mossy fiber input to the granule layer so that the individual granule cell samples different types of mossy fiber input and therefore works as an associative element. Sparse coding, meaning that granule cells are silent under resting conditions and fire just a few spikes when the adequate combination of inputs activates the cell, was thought to be a consequence of this organization. Our findings disagree with the sparse codingpattern discrimination concept in that (1) we did not find a convergence of different types of mossy fiber inputs in granule cells, (2) granule cells with some types of mossy fiber input were not silent at rest, and (3) all granule cells with strong peripheral input fired tremendously strong spike trains when activated appropriately.

A different theoretical viewpoint on the function of the granule cell stems from attempts to explain how the cerebellum might contribute to the timing of responses in classical conditioning and other behavioral paradigms. Various theories of granule cells as temporal pattern generators have been presented, most notably the variations on delay-line coding (for review, see Medina et al., 2000; Medina and Mauk, 2000; Ohyama et al., 2003). These theories were not supported in our recordings, in which granule cells were activated by repeated, uniform stimulations (Fig. 9). In addition, electrical skin stimulation always produced exactly timed EPSP responses (Fig. 5) that looked very similar in different cells. Overall, from our experience of recording from the afferent mossy fibers activated by cutaneous input and joint movement input (Garwicz et al., 1998), we believe that the activation patterns we now observed in granule cells primarily reflect the synchronized activity in presynaptic mossy fibers driven by similar input.

\section{References}

Albus JS (1971) A theory of cerebellar function. Math Biosci 10:25-61.

Apps R, Garwicz M (2005) Anatomical and physiological foundations of cerebellar information processing. Nat Rev Neurosci 6:297-311.

Brickley SG, Cull-Candy SG, Farrant M (1996) Development of a tonic form of synaptic inhibition in rat cerebellar granule cells resulting from persistent activation of $\mathrm{GABA}_{\mathrm{A}}$ receptors. J Physiol (Lond) 497:753-759.

Brickley SG, Revilla V, Cull-Candy SG, Wisden W, Farrant M (2001) Adaptive regulation of neuronal excitability by a voltage- independent potassium conductance. Nature 409:88-92.

Brodal P, Bjaalie JG (1992) Organization of the pontine nuclei. Neurosci Res 13:83-118.

Cathala L, Brickley S, Cull-Candy S, Farrant M (2003) Maturation of EPSCs and intrinsic membrane properties enhances precision at a cerebellar synapse. J Neurosci 23:6074-6085.

Chadderton P, Margrie TW, Häusser M (2004) Integration of quanta in cerebellar granule cells during sensory processing. Nature 428:856-860.

Clendenin M, Ekerot C-F, Oscarsson O (1974) The lateral reticular nucleus in the cat. III. Organization of component activated from ipsilateral forelimb tract. Exp Brain Res 21:501-513.

Cooke JD, Larson B, Oscarsson O, Sjölund B (1971) Organization of afferent connections to cuneocerebellar tract. Exp Brain Res 13:359-377.

D’Angelo E, De Filippi G, Rossi P, Taglietti V (1995) Synaptic excitation of individual rat cerebellar granule cells in situ: evidence for the role of NMDA receptors. J Physiol (Lond) 484:397-413.

DiGregorio DA, Nusser Z, Silver RA (2002) Spillover of glutamate onto synaptic AMPA receptors enhances fast transmission at a cerebellar synapse. Neuron 35:521-533.

Edin BB (2004) Quantitative analyses of dynamic strain sensitivity in human skin mechanoreceptors. J Neurophysiol 92:3233-3243.

Edin BB, Johansson N (1995) Skin strain patterns provide kinaesthetic information to the human central nervous system. J Physiol (Lond) 487:243-251.

Ekerot C-F, Jörntell H (2001) Parallel fibre receptive fields of Purkinje cells and interneurons are climbing-fibre specific. Eur J Neurosci 13:1303-1310.

Ekerot C-F, Jörntell H (2003) Parallel fiber receptive fields: a key to understanding cerebellar operation and learning. Cerebellum 2:101-109.

Ekerot C-F, Larson B (1980) Termination in overlapping sagittal zones in cerebellar anterior lobe of mossy and climbing fiber paths activated from dorsal funiculus. Exp Brain Res 38:163-172.

Ekerot C-F, Garwicz M, Schouenborg J (1991) Topography and nociceptive receptive fields of climbing fibres projecting to the cerebellar anterior lobe in the cat. J Physiol (Lond) 441:257-274.

Garwicz M, Jörntell H, Ekerot C-F (1998) Cutaneous receptive fields and topography of mossy fibres and climbing fibres projecting to cat cerebellar C3 zone. J Physiol (Lond) 512:277-293.

Hamann M, Rossi DJ, Attwell D (2002) Tonic and spillover inhibition of granule cells control information flow through cerebellar cortex. Neuron 33:625-633.

Holtzman T, Rajapaksa T, Mostofi A, Edgley SA (2006) Different responses of rat cerebellar Purkinje cells and Golgi cells evoked by widespread convergent sensory inputs. J Physiol (Lond) 574:491-507.

Houk JC, Buckingham JT, Barto A (1996) Models of the cerebellum and motor learning. Behav Brain Sci 19:368-383.

Jörntell H, Ekerot C-F (2002) Reciprocal bi-directional plasticity of parallel fiber receptive fields in cerebellar Purkinje cells and their afferent interneurons. Neuron 34:797-806.

Jörntell H, Ekerot C-F (2003) Receptive field plasticity profoundly alters the cutaneous parallel fiber synaptic input to cerebellar interneurons in vivo. J Neurosci 23:9620-9631.

King VM, Armstrong DM, Apps R, Trott JR (1998) Numerical aspects of pontine, lateral reticular, and inferior olivary projections to two paravermal cortical zones of the cat cerebellum. J Comp Neurol 390:531-551.

Margrie TW, Brecht M, Sakmann B (2002) In vivo, low-resistance, wholecell recordings from neurons in the anaesthetized and awake mammalian brain. Pflügers Arch Eur J Physiol 444:491-498.

Marr D (1969) A theory of cerebellar cortex. J Physiol (Lond) 202:437-470. 
Medina JF, Mauk MD (2000) Computer simulation of cerebellar information processing. Nat Neurosci 3:1205-1211.

Medina JF, Garcia KS, Nores WL, Taylor NM, Mauk MD (2000) Timing mechanisms in the cerebellum: testing predictions of a large-scale computer simulation. J Neurosci 20:5516-5525.

Niedermeyer E, Lopes da Silva F (1993) Electroencephalography: basic principles, clinical applications, and related fields. Baltimore: Williams and Wilkins.

Ohyama T, Nores WL, Murphy M, Mauk M (2003) What the cerebellum computes. Trends Neurosci 26:222-227.

Oscarsson O, Rosén I (1966) Response characteristics of reticulocerebellar neurones activated from spinal afferents. Exp Brain Res 1:320-328.

Palay SL, Chan-Palay V (1974) Cerebellar cortex. Berlin: Springer.

Pinault D (1996) A novel single-cell staining procedure performed in vivo under electrophysiological control: morpho-functional features of juxtacellularly labeled thalamic cells and other central neurons with biocytin or neurobiotin. J Neurosci Methods 65:113-136.

Rossi DJ, Hamann M (1998) Spillover-mediated transmission at inhibitory synapses promoted by high affinity $\alpha 6$ subunit $\mathrm{GABA}_{\mathrm{A}}$ receptors and glomerular geometry. Neuron 20:783-795.

Schweighofer N, Spoelstra J, Arbib MA, Kawato M (1998) Role of the cerebellum in reaching movements in humans. II. A neural model of the intermediate cerebellum. Eur J Neurosci 10:95-105.

Schweighofer N, Doya K, Lay F (2001) Unsupervised learning of granule cell sparse codes enhances cerebellar adaptive control. Neuroscience 103:35-50.

Semyanov A, Walker MC, Kullmann DM, Silver RA (2004) Tonically active
GABAA receptors: modulating gain and maintaining the tone. Trends Neurosci 27:262-269.

Silver RA, Traynelis SF, Cull-Candy SG (1992) Rapid-time-course miniature and evoked excitatory currents at cerebellar synapses in situ. Nature 355:163-166.

Silver RA, Cull-Candy SG, Takahashi T (1996) Non-NMDA glutamate receptor occupancy and open probability at a rat cerebellar synapse with single and multiple release sites. J Physiol (Lond) 494:231-250.

Tyrrell T, Willshaw D (1992) Cerebellar cortex: its simulation and the relevance of Marr's theory. Philos Trans R Soc Lond B Biol Sci 336:239-257.

van Kan PLE, Gibson AR, Houk JC (1993) Movement-related inputs to intermediate cerebellum of the monkey. J Neurophysiol 69:74-94.

Wall MJ, Usowicz MM (1997) Development of action potential-dependent and independent spontaneous GABAA receptor-mediated currents in granule cells of postnatal rat cerebellum. Eur J Neurosci 9:533-548.

Wall MJ, Usowicz MM (1998) Development of the quantal properties of evoked and spontaneous synaptic currents at a brain synapse. Nat Neurosci 1:675-682.

Walsh JV, Houk JC, Mugnaini ER (1974) Identification of unitary potentials in turtle cerebellum and correlations with structures in granular layer. J Neurophysiol 37:30-47.

Wolpert DM, Miall RC, Kawato M (1998) Internal models in the cerebellum. Trends Cogn Sci 2:338-347.

Xu-Friedman MA, Regehr WG (2003) Ultrastructural contributions to desensitization at cerebellar mossy fiber to granule cell synapses. J Neurosci 23:2182-2192. 